\title{
Comparison of physical activity questionnaires for the elderly with the International Classification of Functioning, Disability and Health (ICF) - an analysis of content
}

\author{
Katharina G Eckert $^{*+}$ and Martin A Lange ${ }^{\dagger}$
}

\begin{abstract}
Background: Physical activity questionnaires (PAQ) have been extensively used to determine physical activity (PA) levels. Most PAQ are derived from an energy expenditure-based perspective and assess activities with a certain intensity level. Activities with a moderate or vigorous intensity level are predominantly used to determine a person's PA level in terms of quantity. Studies show that the time spent engaging in moderate and vigorous intensity PA does not appropriately reflect the actual PA behavior of older people because they perform more functional, everyday activities. Those functional activities are more likely to be considered low-intense and represent an important qualitative health-promoting activity. For the elderly, functional, light intensity activities are of special interest but are assessed differently in terms of quantity and quality. The aim was to analyze the content of PAQ for the elderly.
\end{abstract}

Methods: $N=18$ sufficiently validated PAQ applicable to adults $(60+)$ were included. Each item $(N=414)$ was linked to the corresponding code of the International Classification of Functioning, Disability and Health (ICF) using established linking rules. Kappa statistics were calculated to determine rater agreement.

Results: Items were linked to 598 ICF codes and 62 different ICF categories. A total of $43.72 \%$ of the codes were for sports-related activities and $14.25 \%$ for walking-related activities. Only $9.18 \%$ of all codes were related to household tasks. Light intensity, functional activities are emphasized differently and are underrepresented in most cases. Additionally, sedentary activities are underrepresented (5.55\%). $\mathrm{k}$ coefficients were acceptable for $\mathrm{n}=16$ questionnaires (0.48-1.00).

Conclusions: There is a large inconsistency in the understandings of PA in elderly. Further research should focus (1) on a conceptual understanding of PA in terms of the behavior of the elderly and (2) on developing questionnaires that inquire functional, light intensity PA, as well as sedentary activities more explicitly.

Keywords: Physical activity, Elderly, Questionnaires, Content analysis, International Classification of Functioning, Disability and Health (ICF)

\section{Background}

The evidence regarding correlations between physical activity and health-related outcomes for older people has rapidly grown in the last decade. Physical activity can help maintain overall health, recover from injuries faster, and slow down age-related decline in physical and mental functioning $[1,2]$ or the progress of chronic

\footnotetext{
* Correspondence: katharina.eckert@uni-leipzig.de

${ }^{\dagger}$ Equal contributors

Institute of Exercise and Public Health, Faculty of Sport Science, University Leipzig, Jahnallee 59, 04109 Leipzig, Germany
}

diseases [3,4]. In the context of advanced age, functional activities in everyday life such as carrying groceries, climbing stairs or going for a walk become more relevant than other activities, e.g., sports activities, because those activities maintain an individual's independence and health-related quality of life $[5,6]$.

The growing scientific and applicatory interest in the field of physical activity has led to an extensive endeavor resulting in a variety of physical activity questionnaires (PAQ) that assess physical activity. The main purpose of these questionnaires is to assess the amount of time 
spent on and frequency of a certain activity in the last 5 up to 365 days. Often information of the intensity level of the activities is also retrieved through questionnaires [7]. However, there are questions regarding several aspects of their validity.

Most existing questionnaires are derived from an energy expenditure-based perspective and assess activities with a certain intensity level because evidence connects higher levels of energy expenditure with a variety of health-promoting effects [8]. The consequence of this emphasis is that activities with a moderate or vigorous intensity level, e.g., sports activities, are predominantly used to determine a person's physical activity level in terms of quantity [5]. Studies show that the time spent engaging in moderate and vigorous intensity physical activity does not appropriately reflect the actual physical activity behavior of older people because they perform more functional, everyday activities [6,9]. Those functional activities are more likely to be considered lowintensity physical activity and represent an important qualitative health-promoting activity [10,11]. Therefore, focusing mainly on activities with a higher rate of energy expenditure leads to a very specific and narrow view of physical activity that misses the majority of activities in which elderly people take part and can generate floor effects by excluding less intense activities $[12,13]$. In addition, sedentary behavior has emerged as an independent risk factor for health among older adults [14], but is not sufficiently covered by most of the questionnaires.

A second aspect of consideration that does not only occur in PAQ for the elderly but is more noticeable in these measurement instruments is the highly variable content of PAQ [15]. In the context of physical activity, Pettee Gabriel et al. [16] presented a conceptual framework defining physical activity as "a complex and multidimensional behavior that does not stand in isolation from other related constructs, including sedentary behavior, energy expenditure, and physical fitness" (p.15). Based on their proposed conceptual framework, the authors specifically understand physical activity "as the behavior that involves human movement, resulting in physiological attributes including increased energy expenditure and improved physical fitness". Within that framework, four general domains have been noted, (a) leisure time physical activities, (b) work- or school-related activities, (C) household, and (d) transport activities. The global construct of interest in this model is "human movement". It reflects the directional relationship between the behavioral aspect of human movement, the characteristic, and the physiological result (energy) of movement for the first time [16].

However, although the authors present a definition and conceptual basis of the four domains mentioned above, the term 'physical activity' remains broad and wide ranging, especially in regard to generating and interpreting the outcome. Williams et al. [17] identified 104 questionnaires that measure physical activity in elderly and chronically ill populations and analyzed the content and format of those instruments on the domain level. The analysis notes a broad lack of agreement regarding content and format. To date, there is no consistency about exactly how to measure physical activity in the elderly or, in other words, "what to ask". A more detailed analysis of questionnaires not only on a domain level but on an item level has to be done.

The aim of the study was to analyze the content of PAQ for the elderly. Specifically, we want to (1) identify common PAQ for the elderly, (2) link every item to the International Classification of Functioning, Disability and Health (ICF), (3) analyze their content and finally (4) discuss the findings with regard to the described conceptual framework. The findings should support users in choosing an adequate instrument for a specific context or purpose.

\section{Methods}

\section{Selection of measures}

The research approach was based on the PRISMA guidelines (Preferred Reporting Items for Systematic Reviews and Meta-Analyses) [18]. The literature search took place in March 2013 using three major databases for social sciences (PubMed, EBSCO HOST and SportDiscus). We searched for PAQ using the following keywords with Boolean operators (AND, OR) in titles and abstracts: "questionnaire", "scale", "index", "physical activity", "activity", "sport", "exercise", "adults", "adolescents", "older" and "elderly". 784 articles were identified through the database search and an additional 22 articles through independent web research $(\mathrm{N}=806)$. We removed 751 duplicates, which were mainly validation studies in different populations, settings or validation approaches. The remaining 55 articles were screened for English language and full access to the questionnaire's items (see Figure 1). Also the applicability for older adults had to be given by either explicitly mentioning the target group of elderly or being validated within the age range of 60 to 90 years. Three PAQ were excluded, the Occupational Physical Activity Questionnaire (OPAC) [19], the Occupational Sitting and Physical Activity Questionnaire (OSPAQ) [20] and the Tecumseh Occupational Physical Activity Questionnaire (Tecumseh OPAQ) [21] because they were only applicable in occupational contexts. Due to the fact that we wanted to analyze the content of questionnaires assessing the physical activity levels of older people, the administration mode was less relevant. Therefore, we included both interview-based and self-administered instruments. 


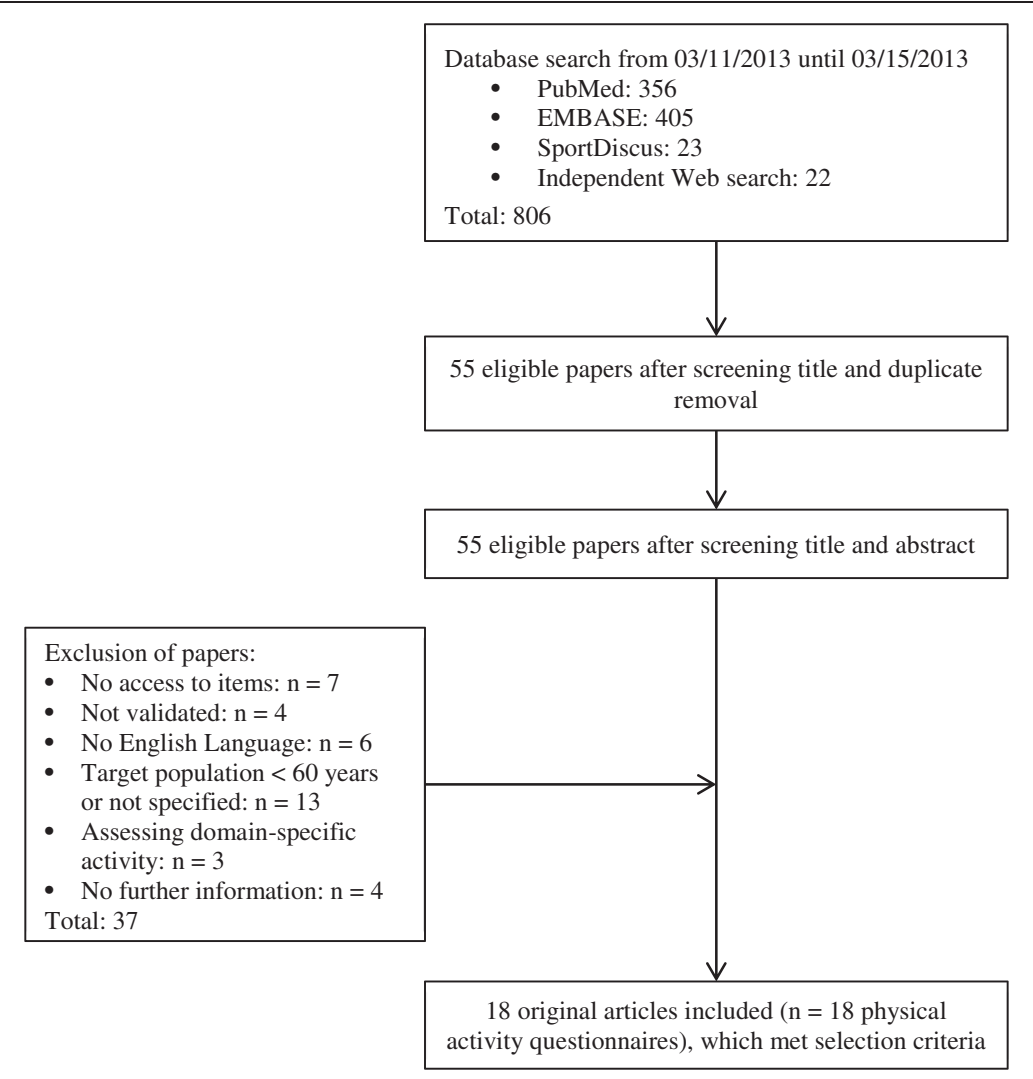

Figure 1 Flow diagram of the search procedure.

The remaining PAQ $(n=18)$ contained a total of 414 items (every item refers to a question) and 85 context based physical activity categories varying from 8 to 77 items and 1 to 10 domains per instrument. The characteristics of the included PAQ are presented in Table 1.

\section{The International Classification of Functioning, Disability and Health (ICF)}

The ICF is an international classification system developed by the World Health Organization [38]. The four ICF components (body functions, body structures, activity and participation, and environmental factors) consist of 1454 categories that are hierarchically arranged into chapters and levels. The biopsychosocial approach of the ICF provides a conceptual basis for the definition and measurement of functioning, disability and health. With its systematic coding scheme, the ICF functions as a common language to describe health and health-related states. All categories are defined by a unique code made up of (1) a letter representing the ICF component (2) followed by a numeric code representing the chapter level (first digit), the second level (next two digits) and the third level (fourth digit) (see Table 2).

The following ICF codes were choosen for the linking procedure in equivalence to the four domains of the conceptual framework of Pettee-Gabriel et al. [16] to ensure common ground:

- Occupational activities are linked to d850

- Domestic activities are linked to ICF codes equal to d640 and d650 or higher

- Transport activities are linked to ICF codes equal to d470 and d450 or higher and

- Leisure-time activities are represented mainly through ICF codes equal to d920 or higher

Existing rules have been used to link content from instruments to the described hierarchical coding system $[39,40]$ so that PAQ could be compared on a content basis.

\section{Linking procedure}

Each item $(n=414)$ contained in the PAQ was linked to a code in the ICF. The linking procedure was conducted separately by two health professionals who were familiar with the ICF using established linking rules [39,40]. A third health professional was consulted to define the best fitting ICF code when the two primary health professionals did not agree on an item.

The main goal of this study was to analyze and discuss the PAQ content. For comprehensibility reasons ICF 
Table 1 Characteristics of included physical activity questionnaires for the elderly

\begin{tabular}{|c|c|c|c|c|c|c|c|}
\hline Physical Activity Questionnaire & Abbreviation & $\begin{array}{l}\text { Total } \\
\text { items }\end{array}$ & $\begin{array}{l}\text { Administration } \\
\text { mode }\end{array}$ & $\begin{array}{l}\text { Studies on } \\
\text { validity }\end{array}$ & Year & $\begin{array}{l}\text { Target group } \\
\text { (in years) }\end{array}$ & $\begin{array}{l}\text { Recall period } \\
\text { (in days) }\end{array}$ \\
\hline 7-Day Physical Activity Recall [22] & 7-Day PAR & 10 & IB & Cr.V & 1985 & 20 to 74 & 7 \\
\hline Australian Activity Survey [23] & AAS & 13 & SA & Cr.V, Cs.V & 2003 & 18 to 75 & 7 \\
\hline $\begin{array}{l}\text { Baecke modified physical activity questionnaire } \\
\text { for the elderly [24] }\end{array}$ & Baecke modified & 12 & SA & Cr.V & 1991 & 63 to 80 & 7 \\
\hline Behavioral Risk Factor Surveillance System [25] & BRFSS & 8 & $\mathrm{IB}$ & Cr.V & 2012 & 18 and older & 7 or 31 \\
\hline Brunel lifestyle physical activity questionnaire [26] & Brunel PAQ & 9 & SA & Cs.V & 2005 & 18 to 73 & 7 \\
\hline $\begin{array}{l}\text { Community Healthy Activities Model Program } \\
\text { for Seniors [10] }\end{array}$ & CHAMPS & 41 & SA & n.s. & 2001 & 65 to 90 & 7 \\
\hline $\begin{array}{l}\text { The European Prospective Investigation into } \\
\text { Cancer Study-Norfolk [27] }\end{array}$ & EPIC-Norfolk & 77 & SA & Cr.V & 2002 & 45 to 74 & 7 and 365 \\
\hline $\begin{array}{l}\text { The European Prospective Investigation into } \\
\text { Cancer Study-Short Form [28] }\end{array}$ & EPIC-S & 11 & SA & Cr.V & 2003 & 20 to 70 & 7 \\
\hline Global Physical Activity Questionnaire [29] & GPAQ & 16 & SA & Cr.V & 2003 & 18 to 75 & 7 \\
\hline $\begin{array}{l}\text { International Physical Activity Questionnaire } \\
\text { (Long Version) [30] }\end{array}$ & IPAQ-Long & 27 & SA, IB & Cr.V & 1999 & 18 to 65 & 7 \\
\hline $\begin{array}{l}\text { Minnesota Leisure Time Physical activity } \\
\text { Questionnaire [31] }\end{array}$ & $\begin{array}{l}\text { Minnesota } \\
\text { LTPAQ }\end{array}$ & 60 & IB & Cr.V & n.s. & 25 to 75 & 365 \\
\hline Morgenstern Physical Activity Questionnaire [32] & PAQ-M & 14 & SA & Cr.V & 2011 & n.s & 7 \\
\hline Physical activity scale for the elderly [33] & PASE & 19 & SA & Cr.V & 1993 & 65 and older & 7 \\
\hline Rapid Assessment of Physical Activity [34] & RAPA & 12 & SA & Cr.V & 2006 & 50 and older & 7 \\
\hline Stanford Brief Activity Survey [35] & SBAS & 10 & n.s. & Cr.V & 2006 & 60 to 69 & 1 to 7 \\
\hline $\begin{array}{l}\text { Short Questionnaire to assess health-enhancing } \\
\text { physical activity [36] }\end{array}$ & SQUASH & 11 & SA & Cr.V & 2002 & 18 to 65 & 7 \\
\hline Yale Physical Activity Survey [9] & YPAS & 36 & SA & Cr.V & 1988 & 60 to 86 & 7 \\
\hline $\begin{array}{l}\text { Physical Activity Questionnaire from the Zutphen } \\
\text { Cohort of the Seven Country Study [37] }\end{array}$ & Zutphen & 28 & n.s. & Cr.V & 1997 & 65 to 84 & 7 \\
\hline
\end{tabular}

\# - number; SA - Self-administered; IB - Interview-based; o.v. - original version; Cr.V. - Criterion Validity; Ct.V. - Content Validity; Cs.V. - Construct Validity; n.s. - not specified.

codes from the component Activities and Participation (d) in the first part (Functioning and Disability) of the ICF have been used. All concepts of the second part (Contextual Factors) were excluded to assure a solely activity-based analysis.

Three specific linking rules have to be noted because they were frequently present during the linking process. If items contained multiple concepts e.g., cited examples, then each concept was linked to the ICF. Therefore, one item can be linked to more than one ICF category. For example, item number 9 of the EPIC-s [28] "Housework such as cleaning, washing, cooking, child care etc." was linked to d640 ("housework"), d6402

Table 2 Example of the hierarchical taxonomy system of the ICF

\begin{tabular}{lll}
\hline Code & Category & Level \\
\hline$d$ & Activities and Participation & Component level \\
\hline$d 4$ & Mobility & $1^{\text {st }}$ level item \\
\hline$d 450$ & Walking & $2^{\text {nd }}$ level item \\
\hline$d 4501$ & Walking long distances & $3^{\text {rd }}$ level item \\
\hline
\end{tabular}

("cleaning"), d6400 ("washing"), d630 ("cooking") and d660 ("child care"). In contrast, if an item was not assignable because of insufficient information or because it was too general to allow an assignment, the item was classified "nd" (not definable). For example, item number 1 of the RAPA [34] "I rarely or never do any physical activities" was classified as "nd". Items that were not covered by the ICF were classified as "nc" (not covered) such as item number 26 of the Zutphen [37] "What do you think of your pace compared with men of your age?".

\section{Reliability analysis}

For each instrument agreement between the two health professionals was calculated with MedCalc (Version 12.7.5, MedCalc Software bvba, Ostend, Belgium) for the second and third ICF levels using kappa statistics [41]. For these purposes the number of agreements and nonagreements were counted. Based on Altman [42], a kappa between 0.81 to 1 . indicated very good, between 0.61 to 0.8 good, between 0.41 to 0.6 moderate, between 0.21 to 0.4 fair and below 0.2 poor agreement. 


\section{Results}

Overall, the two raters linked 414 items of 18 PAQ to 62 different ICF categories and 598 ICF codes. Additionally, 35 items were classified as "nd", and 10 items were not covered by the ICF ("nc"). The kappa statistics as well as the corresponding confidence intervals showed moderate to very good agreement for 16 of the $18 \mathrm{PAQ}$, ranging from 0.488 to 1.00 . The agreement for items of the Brunel PAQ [26] (kappa: 0.100) and the RAPA [34] (0.014) was poor (Table 3$)$.

In total, 10 of 18 questionnaires contained 'not definable' items. The 35 items classified as 'nd' mainly originated from items asking about time spent being physically active at different intensity levels. Because the understanding of physical activity is very broad, a specific activity or context could not be identified. The majority of items $(83.37 \%)$ of the RAPA [34] were considered 'nd'. Other instruments showing a noticeable amount of 'nd' items were the 7-Day-PAR [22] (50\%) and the Zutphen [37] (21\%).

Most linked ICF codes (98.8\%) were related to the levels mobility (d4), domestic life (d6), major life areas (d8) and community, social and civic life (d9). 405 of 598 ICF codes could be found in the levels mobility (d4) and community, social and civic life (d9). Sport activities in general (d9201), swimming (d4554) and running (d4552) represented $43.72 \%$ of all linked ICF codes, followed by walking ( $\mathrm{d} 450)$ and walking short and long distances

Table 3 Estimated $\mathbf{k}$ coefficient and the bootstrapped confidence intervals at the $2^{\text {nd }}$ and $3^{\text {rd }}$ ICF levels of coding

\begin{tabular}{llllll}
\hline \multirow{2}{*}{ Questionnaire } & \multicolumn{2}{l}{ 2nd level } & & 3rd level \\
\cline { 2 - 3 } K-day PAR & 1.000 & $1.000-1.000$ & & 1.000 & $1.000-1.000$ \\
\hline AAS & 0.689 & $0.471-0.908$ & 0.664 & $0.451-0.877$ \\
\hline Baecke modified & 0.651 & $0.410-0.891$ & 0.603 & $0.383-0.823$ \\
\hline BRFSS & 0.488 & $0.124-0.853$ & 0.488 & $0.124-0.853$ \\
\hline Brunel PAQ & 0.100 & $0.066-0.266$ & 0.100 & $-0.066-0.266$ \\
\hline CHAMPS & 0.736 & $0.606-0.867$ & 0.625 & $0.496-0.754$ \\
\hline EPIC Norfolk & 0.827 & $0.749-0.904$ & 0.727 & $0.640-0.815$ \\
\hline EPIC-S & 0.667 & $0.468-0.866$ & 0.454 & $0.257-0.650$ \\
\hline GPAQ & 0.950 & $0.855-1.000$ & 0.861 & $0.717-1.000$ \\
\hline IPAQ-Long & 0.668 & $0.532-0.804$ & 0.577 & $0.447-0.708$ \\
\hline Minnesota LTPAQ & 0.660 & $0.536-0.784$ & 0.542 & $0.420-0.664$ \\
\hline PAQ-M & 0.874 & $0.760-0.988$ & 0.783 & $0.665-0.901$ \\
\hline PASE & 0.777 & $0.631-0.923$ & 0.596 & $0.450-0.741$ \\
\hline RAPA & 0.014 & $-0.017-0.045$ & 0.043 & $-0.014-0.100$ \\
\hline SBAS & 0.836 & $0.717-0.955$ & 0.649 & $0.507-0.791$ \\
\hline SQUASH & 0.830 & $0.678-0.982$ & 0.580 & $0.386-0.774$ \\
\hline YPAS & 0.787 & $0.656-0.981$ & 0.612 & $0.478-0.747$ \\
\hline Zutphen & 0.633 & $0.470-0.795$ & 0.605 & $0.447-0.763$ \\
\hline
\end{tabular}

(d4500 and d4501) with 14.25\%. Domestic activities, such as doing laundry (d6400), doing kitchen work (d6401), cleaning the household (d6402 and $\mathrm{d} 6403$ ) and disposing garbage (d6405), were less frequently linked (9.18\%). Similar results were found for activities, such as taking care of others (d6600, d6601, d6604) with 2.89\%, taking the stairs (d4453) with $3.14 \%$, using a bicycle (d4750) with $7.00 \%$ and activities implying upper body movement, such as lifting and carrying objects (d430, d4300, d4301) with 5.7\%.

In addition to analyzing the amount of identified ICF codes, it is important to look at the number of questionnaires containing those ICF codes because this value represents the degree of discrepancy between questionnaires. Sports (d9201) is the only ICF concept that is covered by each instrument. Depending on the ICF code and level, walking activities and yard work are investigated by most instruments (11 to 14 instruments), whereas domestic activities are asked about considerably less frequently ( 2 to 10 instruments). Occupational activities such as paid work ( $\mathrm{d} 850)$ and unpaid work ( $\mathrm{d} 855)$ are defined by 6 to 11 instruments and care-taking activities (d6600, d6601, d6604) are covered by 1 to 6 instruments (Table 4).

The results of the linking procedure indicate that only 5 (EPIC-Norfolk [27], EPIC-s [28], IPAQ-Long [30], PAQ-M [32], PASE [33]) out of 18 questionnaires Table 4) contain items referring to all four domains. Taking the number of items into account, the EPIC-Norfolk [27] ( $\mathrm{n}=77$ items) showed a high variability of ICF codes $(\mathrm{n}=98)$ covering all four domains and simultaneously having a strong focus on low-intensity, functional physical activities such as household chores and care-taking activities. A high variability of ICF concepts $(\mathrm{n}=44)$ but fewer items $(\mathrm{n}=14)$ was found in the $P A Q-M$ [32], which also covered all four domains. The remaining 13 instruments showed a large discrepancy in the domestic and occupational domains, whereas leisure-time activities, mainly due to the activity sports (d9201), are covered by each instrument.

Another important aspect of a person's total physical activity behavior is their sedentary behavior. Sedentary activities, such as sitting or lying, increase with age and can have significant health-compromising effects independent of a person's physical activity behavior [43]. The assessment of sedentary activities helps to appropriately appraise the health-enhancing effect of physical activity. Overall sedentary activities are clearly underrepresented with $5.55 \%$ of 598 ICF codes. 9 out of 18 questionnaires acquire information about sitting (d4103, d4153), and 2 out of 18 questionnaires include items referring to lying (d4100, d4150). 7 questionnaires (AAS [23], Baecke modified [24], BRFSS [25], Brunel PAQ [26], CHAMPS [10], Minnesota LTPAQ [31] and RAPA [34]) do not ask about any sedentary activities. 
Table 4 Frequency of items in each PAQ linked to an ICF category

\begin{tabular}{|c|c|c|c|c|c|c|c|c|c|c|c|c|c|c|c|c|c|c|}
\hline & $\begin{array}{l}\text { 7-day } \\
\text { PAR }\end{array}$ & AAS & $\begin{array}{l}\text { Baecke } \\
\text { modified }\end{array}$ & BRFSS & $\begin{array}{l}\text { Brunel } \\
\text { PAQ }\end{array}$ & CHAMPS & $\begin{array}{l}\text { EPIC } \\
\text { Norfolk }\end{array}$ & EPIC-s & GPAQ & $\begin{array}{l}\text { IPAQ- } \\
\text { Long }\end{array}$ & $\begin{array}{l}\text { Minnesota } \\
\text { LTPAQ }\end{array}$ & PAQ-M & PASE & RAPA & SBAS & SQUASH & YPAS & Zutphen \\
\hline Total \# of questionnaire items & 10 & 13 & 12 & 8 & 9 & 41 & 77 & 11 & 16 & 27 & 60 & 14 & 19 & 12 & 10 & 11 & 36 & 28 \\
\hline Total \# of ICF categories & 14 & 20 & 15 & 11 & 9 & 52 & 98 & 23 & 23 & 43 & 72 & 44 & 37 & 2 & 44 & 17 & 48 & 26 \\
\hline \multicolumn{19}{|l|}{ Learning \& Applying Knowledge } \\
\hline d166: Reading & & & & & & 1 & & & & & & & 1 & & 2 & & & \\
\hline d170: Writing & & & & & & & & & & & & & & & 1 & & & \\
\hline \multicolumn{19}{|l|}{ Communication } \\
\hline d330: Speaking & & & & & & & & & & & & & & & 1 & & & \\
\hline d3601: Using communication device & & & & & & 1 & & & & & & & & & & & & \\
\hline \multicolumn{19}{|l|}{ Mobility } \\
\hline d4100: Lying down & & & & & & & 1 & & & & & & & & & & & \\
\hline d4103: Sitting & & & & & & & & & 1 & & & & & & & & & \\
\hline d4104: Standing & & & & & & & 1 & & & & & & & & & & & \\
\hline d4150: Maintaining a lying position & 2 & & & & & & & & & & & & & & & & & 2 \\
\hline d4151: Maintaining a squatting position & & & & & & & 1 & & & & & & & & & & & \\
\hline d4152: Maintaining a kneeling position & & & & & & & 1 & & & & & & & & & & & \\
\hline d4153: Maintaining a sitting position & & & & & & & 2 & 1 & 1 & 2 & & 4 & 2 & & 2 & 1 & 2 & \\
\hline d4154: Maintaining a standing position & & & & & & & 4 & 1 & & & & 1 & 1 & & 1 & 1 & 1 & \\
\hline d430: Lifting and carrying objects & & & & & & & 1 & & & & & 1 & 2 & & 2 & & & \\
\hline d4300: Lifting & & & & & & & 2 & & & 2 & & & & & & 1 & & \\
\hline d4301: Carrying in the hands & & & & & & & 2 & 1 & 2 & 3 & 1 & & & & 2 & 1 & 1 & \\
\hline d4402: Manipulating & & & & & & & & & & & & & & & & & 1 & \\
\hline d445: Hand and arm use & & & & & & & & & & & & 2 & 2 & & 2 & & & \\
\hline d4450: Pulling & & & & & & 1 & & & & & 1 & & & & & & & \\
\hline d4451: Pushing & & & & & & & 1 & & & & & & & & & & & \\
\hline d4453: Turning or twisting hands or arms & & & & & & & & 1 & & & & & & & & & & \\
\hline d450: Walking & & & & 1 & & 5 & 3 & & & & 2 & 2 & 4 & & 3 & & 3 & 5 \\
\hline d4500: Walking short distances & & & & & & & 2 & 1 & & 1 & & 1 & 1 & & & & 1 & \\
\hline d4501: Walking long distances & & 3 & & & & & & 1 & 2 & 6 & 3 & 2 & & & 1 & 1 & 4 & 1 \\
\hline d4502: Walking on different surfaces & & & & & & 1 & 1 & & & & 1 & & & & & & & \\
\hline d4551: Climbing stairs & & 1 & 1 & & & & 4 & 1 & & 1 & 2 & & 1 & & & & 1 & 1 \\
\hline d4552: Running & & 2 & & 1 & & 1 & 2 & 1 & 1 & 1 & 2 & 1 & 1 & & 3 & & & \\
\hline d4554: Swimming & & 2 & & & & 2 & 2 & 1 & 1 & 2 & 2 & 1 & 1 & & 1 & & 1 & \\
\hline d460: Moving around in different locations & & & & & & & & & & & & & & & & & 1 & \\
\hline d4601: Moving around outside the home* & & & & & & & & & & & & & 1 & & & & & \\
\hline d470: Moving around using transportation & & & 2 & & & & & & & & & & & & & & & \\
\hline d4701: Using human-powered vehicles & & & & & & & & & & 2 & & & & & & & & \\
\hline d4702: Using public motorized transportation & & & & & & & 2 & & & 2 & & & & & & & & \\
\hline
\end{tabular}


Table 4 Frequency of items in each PAQ linked to an ICF category (Continued)

\begin{tabular}{|c|c|c|c|c|c|c|c|c|c|c|c|c|c|c|c|c|c|c|}
\hline & $\begin{array}{l}\text { 7-day } \\
\text { PAR }\end{array}$ & AAS & $\begin{array}{l}\text { Baecke } \\
\text { modified }\end{array}$ & BRFSS & $\begin{array}{l}\text { Brunel } \\
\text { PAQ }\end{array}$ & CHAMPS & $\begin{array}{l}\text { EPIC } \\
\text { Norfolk }\end{array}$ & EPIC-s & GPAQ & $\begin{array}{l}\text { IPAQ- } \\
\text { Long }\end{array}$ & $\begin{array}{l}\text { Minnesota } \\
\text { LTPAQ }\end{array}$ & PAQ-M & PASE & RAPA & SBAS & SQUASH & YPAS & Zutphen \\
\hline d4750: Driving human-powered transportation & & 2 & & & & 2 & 5 & 1 & 3 & 4 & 1 & & 2 & & 2 & 2 & 1 & 4 \\
\hline d4751: Driving motorized vehicle & & & & & & 1 & 4 & & & 2 & 1 & 1 & & & 3 & & & \\
\hline \multicolumn{19}{|l|}{ Domestic life } \\
\hline d6200: Acquisition of goods and services & & & 2 & & & 1 & 2 & 1 & & & & 1 & & & & & & \\
\hline \multicolumn{19}{|l|}{ d6300: Preparing simple meals } \\
\hline d6301: Preparing complex meals & & & 1 & & & & 1 & 2 & & & & & & & & 1 & 2 & \\
\hline d640: Doing housework & 3 & & & & & & & & & & 1 & 2 & & & 1 & & & 2 \\
\hline d6400: Washing and drying clothes* & & & & & & & 1 & & & & & & & & & & 1 & \\
\hline d6401: Cleaning cooking area and utensils & & & 1 & & & & 1 & & & & & 1 & & & & 1 & 1 & \\
\hline d6402: Cleaning living area & & & 3 & & & 2 & 1 & 2 & & 2 & & 1 & 2 & & 1 & 1 & 2 & \\
\hline d6403: Using household appliances & & & & & & & & & & & & 1 & & & & & 1 & \\
\hline d6405: Disposing garbage & & & 1 & & & & & & & & & & & & & & 2 & \\
\hline d650: Caring for household objects & 3 & & & & & & & & & & & & & & & & & 1 \\
\hline d6500: Making and repairing clothes & & & 1 & & & & 1 & & & & & & & & & 1 & 2 & \\
\hline d6501: Maintaining dwelling and furnishings & & & & & & 1 & 1 & 1 & & & 4 & 2 & 1 & & 1 & & 2 & 1 \\
\hline d6503: Maintaining vehicles & & & & & & 1 & & & & & & 1 & & & 1 & & 1 & \\
\hline d6505: Taking care of plants, indoors and outdoors & & 2 & & 1 & & 2 & 4 & 1 & & 4 & 5 & 3 & 2 & & 4 & 1 & 4 & 2 \\
\hline d6506: Taking care of animals & & & & & & & & & & & & & & & & & & 1 \\
\hline d6600: Assisting others with self-care & & & & & & & 2 & 2 & & & & 1 & 1 & & & 1 & 1 & \\
\hline d6601: Assisting others in movement & & & & & & 1 & & & & & & 1 & & & & & 1 & \\
\hline d6604: Assisting others in nutrition & & & 1 & & & & & & & & & & & & & & & \\
\hline \multicolumn{19}{|l|}{ Major life areas } \\
\hline d850: Remunerative employment & 3 & & & & 1 & & 14 & 3 & 6 & 5 & 3 & 4 & 5 & & 4 & 2 & & \\
\hline d855: Non-remunerative employment & & & & & & 1 & 1 & & & 1 & & 4 & 1 & & & 1 & & \\
\hline \multicolumn{19}{|l|}{ Community, social and civic life } \\
\hline d910: Community life & & & & & & 1 & & & & & & & & & & & & \\
\hline d920: Recreation and leisure & & & & & & & & & & & 7 & & & & & & & \\
\hline d9200: Play & & & & & & 1 & & & & & & 1 & & & 1 & & & \\
\hline d9201: Sports & 3 & 8 & 2 & 8 & 8 & 18 & 25 & 1 & 6 & 3 & 36 & 3 & 5 & 2 & 5 & 1 & 10 & 5 \\
\hline d0902: Arts and culture & & & & & & 3 & 1 & & & & & & & & & & & \\
\hline d9203: Crafts & & & & & & 1 & & & & & & 1 & 1 & & & & 1 & \\
\hline d9204: Hobbies & & & & & & & 1 & & & & & 1 & & & & & & 1 \\
\hline d9205: Socializing & & & & & & 3 & 1 & & & & & & & & & & & \\
\hline d9300: Organized religion & & & & & & 1 & & & & & & & & & & & & \\
\hline Not definable - physical activity & 5 & & 2 & & & 1 & 7 & & 1 & & & & 1 & 10 & & 1 & 1 & 6 \\
\hline Not classified & & 5 & 1 & & & & 3 & & & & & & & & & & & \\
\hline
\end{tabular}

*Due to the length, the original ICF category is truncated. Full length and description can be found in the ICF [38]. 


\section{Discussion}

Each instrument included in this study was validated against different criteria. When considering validity, not only are criterion and construct validity important but also content validity because it has a major impact on the outcome variable [17]. To the authors' knowledge, PAQ for the elderly have not been analyzed regarding their content on an item-based level. Despite methodological challenges, the ICF provides a comprehensive framework to compare and evaluate the content of PAQ. Overall, the results of the content analysis revealed inconsistencies in the understanding of physical activity between instruments and, subsequently, heterogeneity in its assessment.

Major differences were found on the domain level. Only 4 PAQ clearly covered the four recommended physical activity domains leisure time, occupation, transport and household. The majority of questionnaires contain domains that concentrate on the quality of an activity (e.g., "walking"), summarize certain activities under a broader domain (e.g., "doing odd jobs", "do-ityourself-activities" or "lifestyle activities") or examine activities from an energy-based perspective (e.g., "light", "moderate" or "vigorous" activities). This broad spectrum of physical activity domains reflects the high variability in the physical activity behavior in the elderly and underlines the necessity of assessing other relevant activities in addition to moderate and vigorous intensity activities [44]. At the same time, the differences indicate the need for a standardized conceptual framework of physical activity. Within the analyzed instruments, the occupational domain seemed to be used inconsistently, implying that this domain might be dispensable for a majority of people but at once relevant for self-employed, part-time or volunteer workers. For the sake of completeness and comparability, the adherence to minimum requirements, such as the assessment of the four standardized domains - occupation, household, leisure time and transport - is essential regardless of age [7].

In view of the ICF codes, the lack of agreement of the understanding of physical activity becomes even more evident as the differences on the domain level are aggrandized at the item level. Based on the linkage results, there are a few items, such as sports (d9201) or walking activities (d450, d4500, d4501), that assess the same content and are covered by most questionnaires. Overall, the majority of ICF codes vary in quantity and quality. In this case, quality stands for the ICF level on which the items were linked to. While some questionnaires ask for activities which were identified on the $2^{\text {nd }}$ level, others differentiate an activity more precisely on the $3^{\text {rd }}$ level. Additionally, the results indicate that the selected measures mainly focus on activities that are associated with higher energy expenditure. Light intensity activities that serve a more functional purpose, such as household chores (d640 and higher, d650 and higher) or recreational activities, such as hobbies (d9204) or social activities (d9205), are considered remarkably less often, even though light intensity activities represent the largest part of daily physical activity $[6,45]$. Healy et al. [45] report that over $90 \%$ of waking hours are "spent either in sedentary or in light-intensity activity" (p. 371). Although the health benefits of moderate to vigorous intensity activities cannot be replaced, the benefits of light-intensity activities are evident and can be observed in the reduction of sedentary time [5] and in increased total daily energy expenditure [45]. Additionally, living a physically active lifestyle preserves the physical functionality of the elderly [3] and therefore substantially contributes to a person's quality of life [46].

There are different reasons for the lack of agreement regarding the definition of physical activity and its assessment via self-report methods. First, the context and the scientific era in which an instrument was developed have to be considered. Developing from a fitness paradigm that mainly emphasized vigorous intensity, performance-enhancing activities such as aerobic power or endurance and muscular strength activities, the health paradigm also focused on moderate intensity activities and accumulation of 30 minutes of them throughout the day on most days of the week [8]. With regard to the physical activity behavior of the elderly, both paradigms examine a small window of physical activity, resulting in floor effects. From these energy-related perspectives, single approaches considering the predominant sedentary and light intensity activities of older adults originated e.g., the CHAMPS [10], the PAQ-M [32] or the YPAS [9]. Although these derived questionnaires represent a broader and more accurate range of activities, they were developed for different purposes (e.g. some questionnaires concentrate solely on a certain domain like occupational or lifestyle activities, whereas others focus on specific intensity categories) and therefore did not adhere to a conceptual framework of physical activity, which may have caused the identified content-based differences.

Furthermore, the use of energy-based domains such as light, moderate or vigorous intensity physical activity, e.g., the 7-Day PAR [22], is less conclusive and leaves room for interpretation of which actual activities to assess. This is relevant for researchers developing questionnaires as well as for test subjects with different understandings of the terms light, moderate and vigorous intensity.

\section{Methodological considerations}

In addition to the discussion of the results, it is important to consider some methodological limitations of this investigation. Some concepts were interpreted differently 
by two raters and therefore linked to two different ICF codes. Although a final consensus was reached, linking decisions were made for each item alone without additional context information about the instrument. Items assessing walking activities with additional information about time (e.g., "for at least 10 minutes") were perceived differently and therefore linked to either d450 or d4501. The same is true for the term "physical activity", which in some questionnaires was used within a certain domain such as recreation, leisure time, household or occupation but was not clearly phrased within the item.

Moreover, questionnaires and their items were listed consecutively for the linking process leading to the assumption (one rater) that a question's content could be connected to the previous question and therefore impacting the amount of identified concepts. IPAQ-Long [30] questions number 18 ("[...] you do moderate activities like carrying light loads, washing windows, scrubbing floors and sweeping inside your home?") and 19 ("[...] on one of those days doing moderate physical activities inside your home?") exemplify this fact.

A general problem during the linkage and the discussion of those results involved questionnaires containing energy-related items such as "light", "moderate" or "vigorous" intensity activities. Those questionnaires caused an inevitable and predictable discrepancy compared to questionnaires asking about specific activities.

\section{Conclusions}

The main goals of this article were to analyze the content of PAQ for the elderly, discuss the findings with regard to a conceptual framework and derive recommendations for practitioners and researchers. The results indicated a lack of agreement in terms of assessing levels of physical activity by the elderly with self-report measures. This fact becomes evident when looking at the quantity and variability of physical activity domains and actual activities. There are multiple possible causes for the discrepancies between instruments such as the context, the time and the intended purpose of the questionnaires.

At the same time, there is a lack of consistency about the use of light intensity physical activities and their relation to health-promoting effects in the elderly. Up to now, the analyzed questionnaires derived from a somatic-based perspective, where activities with higher energy expenditure rate are in the foreground. In contrast, the content of various instruments such as the CHAMPS [10] or the YPAS [9] indicate more biopsychosocial approaches where light intensity, functional activities in particular are considered. Despite the controversial discussion of the assessment of light intensity physical activities with self-report measures [5,42], light intensity physical activities represent one of the largest parts of daily physical activity in the elderly and therefore reflect a more accurate picture of an older person's physical activity behavior.

This being said, future research should add a biopsychosocial perspective to the existing energy-based approaches. Within the conceptual framework of Pettee Gabriel et al. [16], the energy expenditure and components of physical fitness are declared as the main outcome parameters of physical activity. Due to the mentioned evidence of physical functioning, the healthpromoting effects of light intensity physical activity such as a person's health-related quality of life should be considered within the framework. To draw causal conclusions, compare the results to different populations and derive general recommendations, the assessment of physical activity, especially functional, light intensity physical activity, should be standardized in terms of domains and actual activities. At the same time, questionnaires should consider a broader range of activities for the elderly because age-related degradation processes tend to develop in an asynchronous manner. Therefore, it is possible that one person may still be working part-time or voluntarily and participates in vigorous sports activities while another person at the same age is only able to pursue light to moderate intensity activities.

The results indicated an insufficient assessment of sedentary behavior. Future research, in particular when developing PAQ, should focus on the implementation of questions regarding sedentary behavior as proposed in the conceptual framework by Pettee Gabriel et al. [16]. This is partly important because health-promoting effects can be negated by the health-compromising effects of sedentariness $[17,43]$. The accurate determination and interpretation of the effects of physical activity can only be achieved by assessing both physical activity and sedentary behavior.

The assessment of physical activity is one of the most important aspects in the context of health promotion. Not only are interventions evaluated but also large populations are monitored and state-wide health policies and health care systems are aligned based on the assessed results. PAQ are cost-effective and easily applicable in a large population but, depending on the content, can be at the same time misleading. Many of the PAQ included in this study do not claim to cover all aspects of physical activity and functioning, e.g. the 7-day PAR [22] is intended to assess leisure and occupational physical activity only. In general, each PAQ aims to cover a particular aspect of physical activity. Therefore, instruments assessing physical activity levels should be selected carefully and the results interpreted appropriately with regard to context, population and purpose. 


\section{Competing interests}

The authors declare that they have no competing interests.

\section{Authors' contributions}

$\mathrm{KE}$ and $\mathrm{ML}$ provided equal contribution to the design, realization and interpretation of the linking process, as well as writing sections of drafts, revising based on comments received, and approving the final version. Both authors read and approved the final manuscript.

\section{Acknowledgements}

We would like to thank S. Baumgaertel for the linking assistance and the proof reading.

\section{Received: 14 August 2014 Accepted: 17 February 2015 Published online: 14 March 2015}

\section{References}

1. Rosness TA, Strand BH, Bergem ALM, Engedal K, Bjertness E. Associations between physical activity in old age dementia-related mortality: a population-based cohort study. Dement Geriatr Cogn Disord Extra. 2014:4:410-8.

2. Tolppanen AM, Solomon A, Kulmala J, Kareholt I, Ngandu T, Rusanen M, et al. Leisure-time physical activity from mid- to late life, body mass index, and risk of dementia. Alzheimers Dement. 2014. doi: 10.1016/j. jalz.2014.01.008. [Epub ahead of print].

3. Ashworth NL, Chad KE, Harrison EL, Reeder BA, Marshall SC. Home versus center based physical activity programs in older adults. Cochrane Database of Syst Rev. 2005;1:CD004017.

4. Paterson DH, Jones GR, Rice CL. Ageing and physical activity: evidence to develop exercise recommendations for older adults. Can J Public Health. 2007;98 Suppl 2:69-108.

5. Powell KE, Paluch AE, Blair SN. Physical activity for health: what kind? How much? How intense? On top of what? Annu Rev Public Health. 2011;32(1):349-65

6. Buman MP, Hekler EB, Haskell WL, Pruitt L, Conway $T L$, Cain $\mathrm{KL}$, et al. Objective light-intensity physical activity associations with rated health in older adults. Am J Epidemiol. 2010;172(10):1155-65.

7. Strath SJ, Kaminsky LA, Ainsworth BE, Ekelund U, Freedson PS, Gary RA, et al. Guide to the assessment of physical activity: clinical and research applications: a scientific statement from the American Heart Association. Circulation. 2013;128(20):2259-79.

8. Haskell WL. Evolution of physical activity recommendations. In: Lee I, editor. Epidemiologic methods in physical activity studies. Oxford, New York: Oxford University Press; 2009. p. 283-301.

9. DiPietro L, Caspersen C, Ostfeld A, Nadel E. A survey for assessing physical activity among older adults. Med Sci Sports Exerc. 1993;25(5):628-42.

10. Stewart A, Mills K, King A, Haskell WL, Gillis D, Ritter PL. CHAMPS physical activity questionnaire for older adults: outcomes for interventions. Med Sci Sports Exerc. 2001;33:1126-41.

11. Ip EH, Church T, Marshall SA, Zhang Q, Marsh AP, Guralnik J, et al. LIFE-P Study Investigators: physical activity increases gains in and prevents loss of physical function: results from the lifestyle interventions and independence for elders pilot study. J Gerontol A Biol Sci Med Sci. 2013;68(4):426-32.

12. Tudor-Locke CE, Myers AM. Challenges and opportunities for measuring physical activity in sedentary adults. Sports Med. 2001;31(2):91-100.

13. Shephard RJ. Limits to the measurement of habitual physical activity by questionnaires. Br J Sports Med. 2003;37(3):197-206.

14. de Rezende LFM, Rey-Lopez JP, Matsudo VKR, Carmo Luiz do O. Sedentary behavior and health outcomes among older adults: a systematic review. BMC Public Health. 2014;14:333.

15. Gimeno-Santos E, Frei A, Dobbels F, Rüdell K, Puhan MA, Garcia-Aymerich J. The PROactive consortium: validity of instruments to measure physical activity may be questionable due to a lack of conceptual frameworks: a systematic review. Health Qual Life Outcomes. 2011;9(1):86.

16. Pettee Gabriel KK, Morrow Jr J, Woosley A. Framework for physical activity as a complex and multidimensional behavior. J Phys Act Health. 2012;9 Suppl 1:11-8.

17. Williams K, Frei A, Vetsch A, Dobbels F, Puhan MA, Rüdell K. Patient-reported physical activity questionnaires: a systematic review of content and format. Health Qual Life Outcomes. 2012;10(1):28.
18. Moher D, Liberati A, Tetzlaff J, Altman DG, PRISMA Group. Preferred reporting items for systematic reviews and meta-analyses: the PRISMA statement. PLoS Med. 2009;6(7):e1000097. doi:10.1371/journal.pmed.

19. Reis JP, Dubose KD, Ainsworth BE, Macera CA, Yore MM. Reliability and validity of the occupational physical activity questionnaire. Med Sci Sports Exerc. 2005;37(12):2075-83.

20. Chau JY, Van Der Ploeg HP, Dunn S, Kurko J, Bauman AE. Validity of the occupational sitting and physical activity questionnaire. Med Sci Sports Exerc. 2012;44(1):118-25.

21. Montoye HJ. Estimation of habitual physical activity by questionnaire and interview. Am J Clin Nutr. 1971;24:1113-8.

22. Sallis JF, Haskell WL, Wood P, Fortman SP, Rogers T, Blair SN, et al. Physical activity assessment methodology in the Five-City Project. Am J Epidemiol. 1985;121(1):91-106.

23. Australian Institute of Health and Welfare (AlHW). The active Australia survey: a guide and manual for implementation, analysis and reporting. Canberra: AlHW; 2003.

24. Voorrips LE, Ravelli AC, Dongelmans PC, Deurenberg P, Van Staveren WA. A physical activity questionnaire for the elderly. Med Sci Sports Exerc. 1991;23(8):974-9.

25. Centers for Disease Control and Prevention (CDC). Behavioral risk factor surveillance system survey questionnaire. Atlanta, Georgia: U.S. Department of Health and Human Services, Centers for Disease Control and Prevention; 2012.

26. Karageorghis Cl, Vencato M, Chatzisarantis N, Carron A. Development and initial validation of the Brunel lifestyle physical activity questionnaire. $\mathrm{Br}$ J Sports Med. 2005;39(5):e23-30.

27. Wareham NJ. Validity and repeatability of the EPIC-norfolk physical activity questionnaire. Int J Epidemiol. 2002;31(1):168-74

28. Pols M, Peeters P, Ocké MC, Slimani N, Bueno-de-Mesquita HB, Collette HJ. Estimation of reproducibility and relative validity of the questions included in the EPIC physical activity questionnaire. Int J Epidemiol. 1997;26 Suppl 1:181-9.

29. Bull F, Maslin T, Armstrong T. Global physical activity questionnaire (GPAQ): nine country reliability and validity study. J Phys Act Health. 2009;6(6):790-804.

30. Craig $C L$, Marshall $A L$, Sjöström M, Bauman AE, Booth ML, Ainsworth BE, et al. International physical activity questionnaire: 12-country reliability and validity. Med Sci Sports Exerc. 2003;35(8):1381-95.

31. Taylor H, Jacobs Jr D, Schucker B, Knudsen J, Leon AS, Debacker G. A questionnaire for the assessment of leisure time physical activities. J Chronic Dis. 1978;31(12):741-55.

32. Rubenstein JH, Morgenstern H, Kellenberg J, Kalish T, Donovan J, Inadomi J, et al. Validation of a new physical activity questionnaire for a sedentary population. Dig Dis Sci. 2011;56(9):2678-87.

33. Washburn RA, Smith KW, Jette AM, Janney CA. The physical activity scale for the elderly (PASE): development and evaluation. J Clin Epidemiol. 1993:46(2):153-62.

34. Topolski T, LoGerfo J, Patrick D, Williams B, Walwick J, Patrick M. The rapid assessment of physical activity (RAPA) among older adults. Prev Chronic Dis. 2006;3(4):1-8.

35. Taylor-Piliae RE, Norton L, Haskell WL, Mahbouda MH, Fair JM, Iribarren C, et al. Validation of a new brief physical activity survey among men and women aged 60-69 Years. Am J Epidemiol. 2006;164(6):598-606.

36. Wendel-Vos G, Schuit A, Saris W, Kromhut D. Reproducibility and relative validity of the short questionnaire to assess health-enhancing physical activity. J Clin Epidemiol. 2003;56(12):1163-9.

37. Caspersen C, Bloemberg B, Saris W, Merritt R, Kromhut D. The prevalence of selected physical activities and their relation with coronary heart disease risk factors in elderly men: the Zutphen study, 1985. Am J Epidemiol. 1991;133(11):1078-92.

38. World Health Organization (WHO). International Classification of Functioning Disability and Health: ICF. Geneva: World Health Organization; 2001.

39. Cieza A, Geyh S, Chatterji S, Kostanjsek N, Üstün B, Stucki G. ICF linking rules: an update based on lessons learned. J Rehabil Med. 2005;37(4):212-8.

40. Cieza A, Brockow T, Ewert T, Amman E, Kollerits B, Chatterji S, et al. Linking health-status measurements to the international classification of functioning, disability and health. J Rehabil Med. 2002;34(5):205-10.

41. Cohen J. A coefficient of agreement for nominal scales: educational and psychological measurement. Educ Psychol Meas. 1960;20(1):37-46.

42. Altman DG. Practical statistics for medical research. 1st ed. London, New York: Chapman and Hall; 1991. 
43. Larsen BA, Allison MA, Kang E, Saad S, Laughlin GA, Araneta MR, et al. Associations of physical activity and sedentary behavior with regional fat deposition. Med Sci Sports Exerc. 2014;46(3):520-8.

44. Brawley L, Rejeski WJ, King AC. Promoting physical activity for older adults: the challenges for changing behavior. AJPM. 2003;25(3):172-83.

45. Healy GN, Wijndaele K, Dunstan DW, Shaw JE, Salmon J, Zimmet PZ, et al. Objectively measured sedentary time, physical activity, and metabolic risk: the Australian diabetes, obesity and lifestyle study (AusDiab). Diabetes Care. 2008:31(2):369-71.

46. McAuley E, Konopack JF, Motl RW, Rosengren K, Morris KS. Physical activity and quality of life in older adults: influence of health status and self-efficacy. Ann Behav Med. 2006;31(1):99-103.

\section{Submit your next manuscript to BioMed Central and take full advantage of:}

- Convenient online submission

- Thorough peer review

- No space constraints or color figure charges

- Immediate publication on acceptance

- Inclusion in PubMed, CAS, Scopus and Google Scholar

- Research which is freely available for redistribution 